\title{
La Gramática de Nebrija (1492): un tratado didáctico a través de su tipografía
}

\author{
The Gramática of Nebrija (1492): \\ a didactic treatise and its typography
}

René Pellen

Universidad de Poitiers

RESUMEN: ¿Qué puede aportar al estudio lingüístico, cultural, socio-histórico de la $G C$ el examen minucioso de su estructura en cuadernos y su tipografía? El objetivo de este artículo es ejemplificar las ventajas que presenta el sistema de referenciación que se propuso en el vol. LXXXIX/2, 2009, de la RFE. Analizada por cuadernos en sus diversos aspectos, la tipografía pone de manifiesto las principales características de un texto que es ante todo un tratado didáctico; permite resaltar, además, varias peculiaridades de la prosa renacentista (capítulo, párrafo, enunciado, sintaxis).

Palabras clave: texto, libro, incunables, tipografía, características discursivas, análisis informático.

ABSTRACT: This paper intends to show the potential interest for linguistic, cultural and socio-historical research of a detailed analysis of the structure and typography of the $G C$. The aim of this paper is to show the advantages of a system of reference first proposed in v. LXXXIX/2, 2009, of the RFE. Through close examination of its typography, the main characteristics of the text as a didactic treatise soon appear; it also becomes possible to observe certain features of Renaissance prose as it moves towards modern standards (chapter, paragraph, utterances, syntax).

Keywords: text, book, incunabula, typography, discourse characteristics, computational analysis. 


\section{Del incunable AL TeXto}

En una nota reciente ${ }^{1}$, insistía en la importancia que presentaba para el estudio de los textos antiguos un sistema de referencia exacto, basado en la estructura material de la fuente. El objetivo de este artículo es proponer una nueva lectura de la Gramática castellana ( $G C$ en adelante) a partir de sus características bibliológicas y tipográficas. Libro y texto, aunque se usan estos términos alternativamente, no son sinónimos. En cuanto texto, la $G C$ se compone de libros (5), capítulos (55), párrafos, etc., y un prólogo general, más un prólogo específico (libro V). Como libro, se estructura fundamentalmente en cuadernos (9), folios (67), páginas (134) y líneas (por lo común 34 en cada plana), según un esquema que expresa nítidamente la colación de los bibliógrafos: a $\mathrm{h}^{8} \mathrm{i}^{4}$ (o sea 8 cuadernos de 8 folios más uno de 4 ).

No existe ninguna correspondencia estricta entre ambos sistemas, lo que explica el error habitual que consiste en afectarle al principio del texto el folio 1 cuando ocupa en el incunable el folio $2^{2}$. También explica los problemas que se plantearon a la hora de preparar el texto para su impresión. Solía intervenir en primer lugar el calibrador, que trataba de repartir la materia entre los distintos cuadernos, y luego el cajista. Los problemas que tenían que resolver eran de diversa índole; unos, cuantitativos (extensión de los libros y capítulos...), otros cualitativos, en relación directa con la naturaleza del texto (en este caso, tratado gramatical de carácter didáctico que ostenta una gran variabilidad discursiva: exposición seguida, rupturas, enumeraciones, listas, ejemplificación...). Las distintas operaciones debían conformarse, además, con los límites de la imprenta y el presupuesto. Seguían vigentes en la escritura los modelos de la tradición manuscrita, si bien con la letra de molde y la reivindicación ortográfica de Nebrija se tendía ya a regularizar el texto escrito. Pero el coste final también constituía una preocupación fundamental tanto del impresor como del autor: la $G C$ formaba parte de esos libros utilitarios que se publicaban para satisfacer la «demanda inmediata» (Infantes, 1993, págs. 71-7233) y al respecto hay que tener presente la advertencia del Lexicón:

\footnotetext{
${ }^{1}$ René Pellen, «La referencia en la transcripción (informática) de los textos antiguos. Ejemplos nebrisenses», Revista de Filología Española, LXXXIX/2, 2009, págs. 349-360.

${ }^{2}$ Según información de Julián Martín Abad (carta particular), cabe rectificar dos errores del mencionado artículo. Nota 11: la reproducción que figura en la edición de Anguita (2005) no es del incunable (no indica el autor de donde procede); la primera hoja del incunable, tanto en su recto como en su verso, quedó en blanco. Pág. 358 y n. 23: la referencia I-1255 que aduce el HSMS en el CD de 1999 corresponde en realidad al número del incunable en el Catálogo de incunables de D. García Rojo, no al mismo incunable (BNM I-1778). Le agradezco a J. Martín Abad estas utilísimas aclaraciones.

${ }^{3}$ Víctor Infantes, «1492: una cultura entre el libro y el lector», en P. Ruiz Pérez, ed., Gramática y humanismo. Perspectivas del Renacimiento español, Madrid, Ediciones Libertarias, Ayun-
} 
Estrechamos esso mes/mo el volumen debaxo de una maravillosa / brevedad: por que la grandeza del precio / no espantasse alos pobres delo comprar: ni / la frente alta del libro alos ricos hastiosos / delo leer. $\tau$ tan bien por que mas ligero se pu/diesse traer de un lugar a otro en la mano $\tau$ / seno $\tau$ so el braço. $(4 \mathrm{v} 2: 35-42)^{4}$

Aunque difieren básicamente ambos tipos de estructura, libro y texto comparten las unidades gráficas inferiores a la página (títulos, párrafos, etc.). Por tanto, para descifrar la $G C$ a través de su entramado tipográfico, se han escogido una serie de parámetros cuya fluctuación se observará a lo largo de los cuadernos: foliación, caja de escritura, signos por página, líneas blancas, espacios, párrafos, palabras, cortes (con guión o sin él), puntuación, mayúsculas, abreviaturas, signos restituidos... Mirado al trasluz de este amplio sistema de marcas, cada cuaderno, incluso a veces cada página revelará de qué manera el impresor lleva a cabo el proyecto didáctico de Nebrija, eligiendo diversos modos de representación para tener en cuenta la estrategia del tratado dentro del marco de restricciones técnicas múltiples. Concluirá esta exposición una síntesis recapitulativa sobre las principales estructuras gráficas y lingüísticas del texto.

\section{MARCO GENERAL: INCUNABLE Y TEXTO}

Comienza el texto de la $G C$ en el folio a2r y termina en el i3v. He aquí el cuadro de correspondencias entre ambos sistemas de referenciación, cuya común articulación es el folio.

\footnotetext{
tamiento de Córdoba, 1993, págs. 57-85. El público lector quedaba, sin embargo, bastante limitado: según Gimeno Blay y Trenchs Odena (1992, pág. 214), que se apoyan en las informaciones de Berger, la media aproximada en las bibliotecas de la nobleza era, hasta 1518, de 11 libros; las profesiones liberales y el clero eran los que más libros poseían y donde se encontraban más lectores potenciales; pero en las bibliotecas de los médicos, entre 1474 y 1502 la media no pasaba de los 26 libros, y en las de los juristas, de los 25 (Francisco M. Gimeno Blay y José Trenchs Odena, «Libro y bibliotecas en la Corona de Aragón (siglo XVI)», en P. M. Cátedra García y M. L. López-Vidriero Abello, coords., El Libro antiguo español. Actas del Segundo Coloquio internacional (Sevilla, 1989), Salamanca, Universidad de Salamanca, Madrid, Biblioteca Nacional, Sociedad Española de Historia del Libro, 1992, págs. 207-239). En cuanto a la tirada, fluctuaba entre los 100 ejemplares, para las más reducidas, y los 700; la de Tirant lo Blanch, que alcanzó en 1490 los 750 ejemplares, la califica Julián Martín Abad de «importante» (Los primeros tiempos de la imprenta en España (c. 1471-1520), Madrid, Laberinto, 2003, pág. 155).

${ }^{4}$ Las citas de la $G C$ y los diccionarios se hacen en conformidad con el sistema de referenciación que se expuso en René Pellen (2009); el signo </> indica el paso a la línea no marcado en el incunable; si el texto lleva un guíon, el truncamiento se expresa $<-/>$. Huelga decir que se respeta en todo punto la grafía y presentación del incunable.
} 
Cuadro 1. Correspondencias entre cuadernos y libros

\begin{tabular}{|c|c|c|}
\hline Cuadernos & Folios & Libros y caps. \\
\hline $\mathrm{a}$ & {$[1] \mathrm{dr}-8 \mathrm{v}$} & Pról.-I.4 \\
\hline $\mathrm{b}$ & $9 \mathrm{r}-16 \mathrm{v}$ & I.4-10 \\
\hline $\mathrm{c}$ & $17 \mathrm{r}-24 \mathrm{v}$ & I.10-II.8 \\
\hline $\mathrm{d}$ & $25 \mathrm{r}-32 \mathrm{v}$ & II.8-III.5 \\
\hline $\mathrm{e}$ & $33 \mathrm{r}-40 \mathrm{v}$ & III.5-12 \\
\hline $\mathrm{f}$ & $41 \mathrm{r}-48 \mathrm{v}$ & III.12-IV.4 \\
\hline $\mathrm{g}$ & $49 \mathrm{r}-56 \mathrm{v}$ & IV.4-V.2 \\
\hline $\mathrm{h}$ & $57 \mathrm{r}-64 \mathrm{v}$ & V.2-6 \\
\hline $\mathrm{i}$ & $65 \mathrm{r}-67 \mathrm{v}$ & V.6-11 \\
\hline
\end{tabular}

No coinciden nunca límite de libro y límite de cuaderno, y no facilita los cálculos previos la disproporción entre los libros (16,5 folios para el III, el más extenso / 9,5 para el IV, el más breve). Este contraste expresa ya una fuerte asimetría entre el libro que trata «dela etimologia $\tau$ dicción» (en el que se definen, en realidad, las partes de la oración) y el que versa sobre «sintaxi $\tau$ orden delas d|[ie]z| partes dela oracion ${ }^{5}$ (en el que el autor sólo dedica los primeros cuatro capítulos al tema anunciado, deslizándose en los siguientes de la sintaxis a la retórica). Señala también una ruptura significativa en la exposición gramatical y, en cierto modo, una laguna definitiva tanto en la teoría de Nebrija como en las repercusiones prácticas de su tratado ${ }^{6}$.

Por cierto, los criterios sintácticos afloran en el libro III y sirven, conjuntamente con criterios morfológicos y semánticos, para definir cada una de las diez partes: «Substantivo se llama por que esta por si mesmo: $\tau$ / no se arrima a otro ninguno» (30r21). Pero, a excepción del nombre y el verbo, que se consideran brevemente en los primeros capítulos del libro IV, la $G C$ pasa por alto todo lo que se refiere a los problemas de «orden»(46r16), «construcción» (46v23) y «concordia» (45v8) que plantean las demás partes. Los editores no suelen comentar este repentino cambio de rumbo en el libro $\mathrm{IV}^{7}$ (para más detalles, véase Pellen y Tollis, 2011, § I.7.4 ${ }^{8}$; un breve examen del Cuadro 1 bas-

\footnotetext{
${ }^{5}$ El signo $<>>$ expresa la supresión de algún elemento erróneo (letra, secuencia de letras); aquí, «d|[ie]z|» donde $I$ trae «do-/ze» (45r33).

${ }^{6}$ Pese a lo que sostiene, por ejemplo, Héctor Esparza Torres (Las ideas lingüísticas de Antonio de Nebrija, Münster, Nodus Publikationen, 1995, cap. XII) — sin negar, desde luego, el valor de las aportaciones nebrisenses-.

${ }^{7}$ Antonio Quilis (Antonio de Nebrija, Gramática de la lengua castellana, A. Quilis, ed., Madrid, Editorial Centro de Estudios Ramón Areces, 1990) sólo alude a la «rudimentaria sintaxis» del libro V (pág. 41); pero como los demás editores, se contenta con resumir y glosar sucintamente el contenido de la $G C$.

${ }^{8}$ René Pellen y Francis Tollis, La «Gramática castellana» d'Antonio de Nebrija: grammaire d'une langue, langue d'une grammaire, Limoges, Lambert-Lucas, 2 vols., 2011, 874 págs.
} 
ta, sin embargo, para divisar un verdadero salto desde una descripción más o menos prescriptiva a un repertorio de figuras (a partir del solecismo) ${ }^{9}$.

El libro V no compensa la laguna del libro IV puesto que, como lo expresa su prólogo particular y su mismo título, su objeto, distinto del de los otros libros, es presentar un prontuario de gramática castellana «para los que de estraña lengua querran deprender» (55r21). La exposición se hace esquemática, reduciéndose a unos pocos folios lo que antes se expuso en 30,5 y añadiéndose elementos que no figuraban en el arte propiamente dicho. En realidad, toda la materia de los primeros tres libros viene resumida en el primer capítulo; lo demás es un vademécum sobre la declinación y la conjugación, a pesar de que se haya afirmado rotundamente en 35r11 que «Declinacion del nombre no tiene la lengua castellana» ${ }^{10}$. No cabe duda de que este prontuario puede ser de alguna utilidad para el extranjero que quiera aprender el castellano, pero también es cierto que en los capítulos 2 y 3 el vulgarizador está haciendo pedazos la doctrina que a duras penas estableció el gramatico (mientras se le olvida por completo el libro II sobre prosodia). De todas formas, tanto en la temática como en el método el libro V (interprétese como suplemento ELE o compendio práctico para nativos) añade un componente que acentúa la heterogeneidad del conjunto.

El examen de los distintos parámetros arriba citados permite analizar desde dentro la estructura de la $G C$. Lo que de primera entrada manifiestan los datos tipográficos es la existencia de dos partes muy disímiles (cuads. a-e, fols. 1r-40v $/ f-i, 41 \mathrm{r}-67 \mathrm{v}$ ), que se designarán para mayor comodidad como parte A y parte B.

\section{DOS PARTES DIFERENTES; RASGOS CARACTERÍSTICOS}

A (libros I, II, III) y B (final del libro III, libros IV-V) se oponen en varios planos, singularmente en lo que se refiere a la densidad por página de los

\footnotetext{
${ }^{9} \mathrm{Al}$ mencionar primero el barbarismo, Nebrija da vuelta atrás hacia los criterios morfológicos del libro III ya que, como él mismo precisa, este vicio se produce «en cada una delas partes de la oración: considerando dellas apartada men-/te» (49r8). El solecismo sí corresponde a la sintaxis, pero a diferencia del barbarismo no siempre es vicio «intolerable» (42r18); de ahí la escapatoria hacia los «metaplasmos» (V.6) y el abandono de la descripción sintáctica — desvío que poco antes se dejaba vislumbrar al concluirse el capítulo 4 con una cita de «sinedoque» (49r4)—. Para los gramáticos antiguos y medievales las figuras (al menos las de construcción) pertenecían a la Gramática; sobre este punto, véase Vicente Calvo Fernández, Grammatica Proverbiandi. Estudio de la Gramática Latina en la Baja Edad Media Española, Münster, Nodus Publikationen, 2000 (Materialien zur Geschichte der Sprachwissenschaft und der Semiotik; 11), pág. 150.

${ }^{10}$ Persiste en la $G C$ una contradicción latente, porque Nebrija sigue proyectando sobre el castellano los paradigmas latinos y menciona en varias ocasiones la declinación del nombre (29r25, $34 \mathrm{r} 24,35 \mathrm{r} 15)$, así como la existencia de casos; pero al trasladar al castellano los modelos del latín, vuelve a utilizar una metalengua impropia (ya que no corresponde a ninguna realidad morfológica): «Los casos enel castellano son cinco. el primero / llaman los latinos no[ $m]$ inativo» (35v6).
} 
signos tipográficos $(1438 / 1298)^{11} \mathrm{y}$, correlativamente, a la cantidad de espacios $(317 / 483)^{12}$, o de mayúsculas $(12 / 17)$. En la primera parte, resalta el carácter apretado de la presentación, que expresa la tendencia a colocar en la página un máximo de signos, mientras escasean los espacios y las letras de más bulto. En la segunda, se aligera la presión tipográfica, dándose la preferencia a un texto más holgado: crece paralelamente el número de líneas blancas (A 8 / B 14) y de párrafos externos (pasando de 1,7 a 5,3 por página $)^{13}$, al tiempo que aparecen listas de ejemplos en líneas distintas o columnas de renglón corto $(56 \mathrm{v})$.

Cada uno de estos cambios formales significa una evolución en el enfoque didáctico. Baste comparar dos listas de ejemplos, la relación de 51 esdrújulos en 20v1-11:

Muchas tienen el acento en / la ante penultima como estas.pérdida. uéspeda.bóve /da.búsqueda.mérida.ágreda. úbeda.águeda. pérti-/ga. almáciga. alhóndiga.luziérnaga.málaga.córce-/ga.águila. [...] ${ }^{14}$

con la nómina de 26 participios activos en 41v:

Callado el que calla $[$ sic $]$

Hablado el que habla.

Porfiado el que porfia. [...]

La modificación en el tratamiento de los ejemplos corresponde a dos posturas y técnicas pedagógicas distintas: una que funda el valor demostrativo de la ejemplificación en la acumulación de los testimonios; otra, que confiere a cada

11 Por signos tipográficos se entiende el conjunto de letras, signos de puntuación y guiones, excepto los espacios entre las palabras, que se consideran por separado, con los demás espacios en blanco.

${ }^{12}$ Los espacios incluyen tanto los intervalos entre las palabras como los signos equivalentes de las líneas blancas y los comienzos o finales de líneas incompletas. Para poder contabilizarlos equiparándolos con las letras, estos espacios, más extensos que los intervalos entre palabras, han sido convertidos en signos equivalentes; el equivalente de una línea en blanco es el número medio de caracteres en la página; el equivalente de otro espacio, el valor medio entre las secuencias correspondientes de letras en las líneas superior(es) e inferior(es).

13 Externos se llamarán los párrafos que implican al mismo tiempo un espacio superior a dos blancos y un paso a la línea (p. ej. «moravan. / Assi» 2v2); internos aquellos que sólo destacan une nuevo enunciado introduciendo entre la capital inicial y el texto anterior un mínimo de dos espacios (p. ej. «Reinos. J assi» 3r28). Desde luego se dan casos ambiguos cuando crece el espacio entre los enunciados consecutivos o/y pasa el texto a la línea, como en 39v10 o 40r16, porque se repite un espacio anómalo con paso a la línea (con sangría o sin ella). En cada caso hace falta apreciar la especificidad del contexto. Es muy probable que la imprenta del siglo XV no distinguía de un modo tajante entre ambos tipos de párrafo ([P Bi M] y $[\mathrm{P}(\mathrm{B} i) /(\mathrm{B} i) \mathrm{M}]$ — 'punto', 'blanco(s)', 'mayúscula'-).

${ }^{14}$ La falta casi general de blanco tras punto obliga a introducir en el texto cortes editoriales. 
ejemplo un valor intrínseco y lo presenta como una entidad autónoma. Se observa, de paso, que las citas de poesía gozan de un tratamiento particular; los versos casi siempre figuran fuera de texto (tanto en A [23r12, 23v18] como en B [50r30, 52v21]), si bien en ocasiones se siguen sin paso a la línea (A 19r22, B 52r16) — tratándose como ejemplos los versos aislados (A 18v21-24, B 50r25)—.

Va creciendo el número de mayúsculas; el que escaseen en $\mathrm{A}$ y rara vez aparezcan al inicio de los nombres propios indica claramente que en la $G C$ no prevalece el valor semántico o simbólico en relación con la onomástica: lo más corriente (y tradicional, por lo demás) es escribir los nombres propios con minúscula, reservando las capitales, por un lado, a las menciones de libro y capítulo, por otro a los comienzos de enunciado (y también de verso). Sólo un $15 \%$ de los nombres propios lleva mayúscula (87 de un total de 597: 32 «mena»/ 0 «Mena»; 2 «lebrixa», 2 «nebrissa»/ 0 «Nebrissa»). Vale decir que la mayúscula funciona sobre todo como marca discursiva y sintáctica fuerte, muy vinculada con la gestión de la puntuación (véase Pellen, 2006, § 2.2 y $2.8^{15}$ ).

Esta evolución general mejora, con mucho, la legibilidad del texto. Se expresa, coherentemente, en otros parámetros como el número de palabras (A 378 / B 277), la abundancia en abreviaturas (31 / 17) o dos puntos por página $(12$ / 4) —parámetros correlacionados con el aumento de espacios, párrafos externos, etc. - Mientras que en A coinciden aproximadamente los totales de palabras y espacios $(318 \sim 317)$, en B casi se duplica la cantidad relativa de espacios (277 / 483). Dicho de otra forma, en A se limita el uso del blanco a la separación mínima entre palabras (la reunión y la frecuente ausencia de blanco tras puntuación permiten insertar de vez en cuando un intervalo más largo, o sea párrafos internos, para realzar los cambios de enunciado y las articulaciones del texto); en B, ya no son raras las líneas incompletas y, por otra parte, los párrafos internos $(4,6 / 1,6)$ van sustituidos por párrafos externos $(1,7$ / 5,3), lo que confiere al incunable un aspecto mucho más moderno y más cómodo para aquel que sólo quiere consultarlo rápidamente (IV.6, 49v-50v).

Uno de los elementos gráficos que acentúan la densidad de A es, sin duda alguna, el empleo de abreviaturas. Características de la escritura manuscrita, las abreviaturas suponen un suplemento importante de signos virtuales por página. Se patentiza este volumen al observar que el conjunto de abreviaturas, convertido en letras, ocuparía tres páginas enteras de la $G C$. Si se examina la repartición de este aporte por página, A otra vez ostenta una ventaja sustanciosa con respecto a $\mathrm{B}(39,2$ / 20,9). Lo que demuestra una correlación entre la densidad de la presentación y el uso de abreviaturas, aunque nunca se olvide este recurso

15 René Pellen, «Transcription des incunables, histoire de l'écriture et diachronie. Étude critique de l'édition du V Ventenaire de la Gramática castellana par Esparza et Sarmiento (1992)», Bulletin Hispanique, 108/1, 2006, págs. 67-222. 
tradicional que con tanta facilidad permite ahorrar espacio ${ }^{16}$. En A, la $G C$ utiliza casi una abreviatura por línea (31); en B, una cada dos líneas (17). Paradójicamente, Nebrija en su Ortografía (libro I) no habla de este fenómeno gráfico ${ }^{17}$.

Tampoco habla de los dos puntos (2P), un signo de particular importancia en la GC. Sirven, normalmente, para delimitar dos segmentos semántico-sintácticos de un enunciado y siempre van seguidos de minúscula. Entre los $11842 \mathrm{P}$ que se rastrean en la $G C$, sólo se recogen dos casos de mayúscula, muy probablemente erróneos (véase Pellen, 2006, § 2.2): 10r7-8 («eran ociosas:/Por que»), 29r4 («que se dize: Como si»). Indican sobre todo que no está completo el enunciado y por tanto nunca les sigue blanco doble, mayúscula o párrafo (incluso con frecuencia no les sigue ningún espacio); tras la pausa (breve) reanuda la enunciación:

[C]Omo diximos arriba:proprio es dela len-/gua castellana tener el acento agudo enla penultima silaba:o enla ultima cuando las diciones son barbaras o cortadas del latin: $\tau$ enla an-/te penultima mui pocas vezes: $\tau$ aun comun mente en / las diciones que traen consigo en aquel lugar el acen/to del latin. (20r22)

$\mathrm{Su}$ frecuencia en la parte A es claro indicio, por consiguiente, de una exposición que se lleva a cabo mediante enunciados largos en los que abundan los nexos coordinantes (y 160 / 23, o 24 / 6) y subordinantes (que 127 / 33, cuando 16 / 1), los conectores adversativos (mas 27 / 4) o argumentativos (porque 66 / 17). Los objetivos son explicar, demostrar, convencer. En la parte B se acorta el enunciado. Al concluirse el libro III, los objetivos son diferentes: definir (libro IV), compendiar (libro V). Los indicadores tipográficos revelan, pues, en su globalidad, el carácter orientado, heterogéneo y dinámico de la $G C$. Se precisarán ahora las modalidades de la exposición examinando brevemente cada uno de los cuadernos.

\section{DINÁMICA DEL LIBRO (EXAMEN DE LOS CUADERNOS)}

\subsection{Parte A}

\subsubsection{Cuaderno a (1r-8v, Prólogo, I.1-4 «de la orthographia»)}

Se hace palmaria la originalidad de este cuaderno inicial a través de un conjunto de rasgos paralelos o correlativos: si se deja a un lado el cuaderno $h$, que

${ }^{16}$ Mateo Alemán (Ortografía castellana, J. Rojas Garcidueñas, ed., T. Navarro, est. prelim., México, El Colegio de México, 1950) todavía censurará, en 1609, el abuso de abreviaturas (68r, ed. pág. 101) —sin dejar de emplearlas él mismo-.

17 No figuran en la GC, el Lexicón o el Vocabulario, las voces puntuación, puntuar, mayúscula, capital. La GC tampoco menciona el párrafo, pero viene citado en Lex (113r2:1) y Vocab (79r2:6), que incluso trae el verbo parrafar (79r2:7). 
utiliza una caja de escritura más ancha, el primero es el que ostenta la tasa más alta de palabras por página (334, promedio general 301), de signos restituidos (desarrollo de abreviaturas) (56, p. g. 32) y de 2 P (19, p. g. 9), la segunda de abreviaturas (41). Esta densidad excepcional, asociada a una sintaxis muy estructurada, ya aparece en el Prólogo, admirable dechado de retórica académica, que se desenvuelve casi de un tirón y con una frecuencia de $2 \mathrm{P}$ que en varias páginas $(2 \mathrm{r}$ 20,2 v 24, 3v 22) rebaja la media del cuaderno (19). En el principio del libro I, corresponde a una exposición principalmente histórico-teórica, en la que abundan los enunciados largos que exigen unos mojones claros entre los componentes sintácticos de tipo frástico (la tasa de puntos por página es la más baja de la $G C$ : 22, p. g. 50): predomina el discurso teórico y Nebrija no escatima los esfuerzos por orientar convenientemente al lector-alumno, multiplicando las anclas discursivas (enumeración en 5r: «La primera»..., «La segunda»...; fórmulas didácticas en cadena en 8r-v: «veamos primero»..., «E primera mente dezimos assi»..., «faltan esso mesmo»...). Todos estos elementos se integran en una estrategia pedagógica muy compleja (véase Tollis en Pellen y Tollis, 2011, cap. 3). El punto funciona casi exclusivamente como marcador final de enunciado (en 6v, 9 puntos, 8 enunciados, proporción casi idéntica a la del Prólogo en 3v [7 P, 8 E $]^{18}$ ).

Desde un punto de vista estrictamente tipográfico, llama la atención el empleo, casi exclusivo de $a$, de una variante de la $<\mathrm{r}>$, la redonda, de diseño muy similar al del signo tironiano («prologo» 2r5); en este cuaderno se agrupan 70 de las 72 ocurrencias (las otras dos, erráticas, bien pueden proceder de sendos errores a la hora de devolver los tipos a los cajetines: «pronunciamos» 14r6, «por que» 26r31). Es de uso general en la $G C$ la $<\mathrm{r}>$ cuadrada o común, así como en el Lexicón y el Vocabulario. Esta peculiaridad de a bien podría representar, por consiguiente, un fenómeno único en el corpus nebrisense impreso por Juan de Porras, ya que se concentra la mayoría de las apariciones en los folios 7 y 8 , quedando los siguientes sin ningún ejemplo. Ahora bien, entre 8v34 y 9r1 no sólo continúa el texto como si perteneciera a la misma página, sino que sirve de enlace entre ambos folios el guión de «semivo-/cales», lo que supone a un tiempo una gran continuidad y un cambio brusco en el trabajo (permuta de cajas o de cajistas, alguna peripecia en el funcionamiento del taller...). Otros fenómenos de esta clase dejan entrever de cuando en cuando la génesis material del libro y recuerdan oportunamente al lingüista que no puede referirse al autor todo lo que acarrea un texto, porque entre la grafía del original y la grafía del libro media la intervención del impresor.

${ }^{18}$ No se verifica una correspondencia estricta por faltar un punto al final de 3v32 ante [B Por que]; muy a menudo se consideraba el final de línea ante mayúscula como puntuación fuerte (si bien implícita) entre enunciados (véase René Pellen, «Transcription des incunables, histoire de l'écriture et diachronie. Étude critique de l'édition du $\mathrm{V}^{\mathrm{e}}$ Centenaire de la Gramática castellana par Esparza et Sarmiento (1992)», cit., § 2.5), de modo que el esquema correcto es [ØР / B Por que]. 


\subsubsection{Cuaderno b (9r-16v, I.4-10 «de la orthographia»)}

El cuaderno $b$ comparte con el primero varias de las características de la parte A. Presenta el número más elevado de signos tipográficos por página (1475, p. g. 1381), así como de palabras (el mismo que $a$ ) y de puntos (68 - exceptuando $h-$ ), exceso en el sentido de la densidad que viene confirmado por otras peculiaridades (la tasa más baja de blancos, 282, y de mayúsculas, 10). Cualquiera que sea la presión tipográfica debida a errores de cómputo en la preparación del trabajo, estos rasgos, a veces privativos del cuaderno, expresan en alto grado una forma de continuidad en la parte A a la par que una apreciable ruptura en el método expositivo. La continuidad se nota en la compacidad del discurso; pero cambia la temática. En el capítulo I.4 las consideraciones generales de repente ceden el paso a una exposición detalladísima sobre la (orto)grafía, latina y castellana, en la que se encadenan, sin apenas pausas entre los capítulos, fases descriptivas y fases prescriptivas. Dentro de los capítulos, se pasa revista a las distintas letras o grupos de letras, repitiendo un esquema enumerativo que multiplica los párrafos internos; pero en ocasiones se omite el párrafo («paño. La.o.»13v23), y hasta el espacio después de punto final si el nuevo enunciado no coincide con una letra nueva («la.b.en.p.De donde»13r7). El cambio de enfoque también se trasluce en la proliferación de los puntos, fiel reflejo de dos fenómenos que se repiten ininterrumpidamente: las citas de letras (que se escriben entre dos puntos: «La.g.»10v11), a veces múltiples («a.b.d.e.f. m.o.p.r.f.t.z.»9v18), y la profusa ejemplificación —un ejemplo también suele insertarse entre dos puntos («destas diciones.cabra.coraçon.»10r26)—. Por otra parte, escasean las mayúsculas, no sólo porque ocupan mucho espacio, sino porque en la mayoría de los casos se integra la ejemplificación en la descripción didáctica, de modo que el máximo introductor de ejemplos, como ( 879 ocs. en la obra), queda con minúscula: «aquella.u.no es consonante sino vocal.como enestas / diciones huesped.huerto.» (12v9, comp. 12v6, 12v13) ${ }^{19}$.

Por lo general, los ejemplos que se aducen en estos capítulos sobre ortografía son breves, pero Nebrija suele duplicarlos («de lux dezimos luz.de pax paz» 14r22) y en ocasiones los acumula («como de villa villa. de clavis lla/ve.de flamma llama. [...]» 13v15), lo que explica que en una sola página como la $13 \mathrm{v}$ se agrupen nada menos que 115 puntos y también que el cuaderno $b$ reúna la cantidad fabulosa de 1085; comparada con la de los demás cuadernos, esta can-

${ }^{19}$ Esta tendencia a integrar en enunciados complejos los componentes sintácticos de un análisis pormenorizado o una argumentación se extiende a otros subordinantes: «huevo.lo cual ia no es me-/nester si las dos fuerças»... (12v10), cuando no descarta la subordinación en beneficio de una simple coordinación (11v31) o un asíndeton (10v8). 
tidad ofrece un contraste similar al del cuaderno $h$ (1409), dedicado en su práctica totalidad a las declinaciones y conjugaciones con un esquema estrictamente enumerativo. Representan, sin lugar a dudas, las dos cumbres de la $G C$ en materia de ejemplificación enumerativa, aunque se oponen radicalmente los contextos discursivos de los dos cuadernos, por la importancia que se le concede, en $b$, a la descripción analítica, casi inexistente en $h$. Esta característica, por lo demás, es lo que configura al cuaderno $c$ como continuación de $b$.

\subsubsection{Cuaderno c $(17 r-24 v, I .10-I I .8)$}

Este tercer cuaderno prolonga, hasta cierto punto, el cuaderno anterior en cuanto enuncia las «reglas generales del orthographia del castellano» (16v34), concluyendo con ellas el libro I dedicado a este tema, antes de abordar la descripción «dela prosodia $\tau$ silaba» (17v25), que ocupará el resto del cuaderno y principio del cuaderno $d$. En un entorno que sigue siendo de particular densidad, se vuelven a encontrar varios rasgos típicos de $a$ y $b$ : número elevado de palabras por página (338 en $21 \mathrm{v}$ ), profusa ejemplificación, con una abundancia desusada de puntos (134 en 21r, donde Nebrija inserta en el texto una lista de 55 esdrújulos en $<-0>$ ).

Pero los demás parámetros indican que se trata de un cuaderno intermedio (en el marco de la primera parte), si bien algunos de ellos recalcan cierta originalidad: espacios a veces muy raros (236, 244 en 20v-21r), concentración ocasional de $2 \mathrm{P}(23$ en $21 \mathrm{v})$ cuando la exposición se hace nuevamente más teórica y argumentativa, sobre todo después de la única página en la primera parte (la 21r) en la que no se da ningún ejemplo de dicha puntuación, por multiplicarse las enumeraciones de palabras que ejemplifican las diversas terminaciones. Para ahorrar espacio, no se usan en $c$ más apartes que en $b$; y hasta las citas de versos se hacen a renglón seguido: « $\tau$ nuestro juan de mena. Tus casos falaces / fortuna cantamos» (18v22).

Se observan, sin embargo, algunas excepciones a la tendencia general de macicez, que prefiguran la evolución de la parte B. En 20r-21r (cap. II.4) se extienden los párrafos internos de tal forma que se presenta cada letra examinada en un verdadero párrafo externo ( $\sin$ sangría: «/En.e.tienen» 20v17, «/En.i.tienen» 20v21), lo que da mayor realce a cada apartado, usándose párrafos internos para destacar los enunciados de segundo orden («tóque. Sacanse» 20v18). Por otro lado, a partir del capítulo 6 se hacen más numerosas las citas de versos al tratarse de la consonancia; cambia entonces la disposición habitual, empezando cada verso (con mayúscula) al margen izquierdo ( «/Las grandes hazañas» 23r12), lo que no impide, si lo permite la brevedad de la cita, introducir algún comentario en la parte derecha de la misma línea: 
como Juan de Mena.

Despues quel pintor del mundo.por dezir.

Despues que el pintor de el mundo. (24r10)

Estas elecciones en la composición del incunable, obviamente relacionadas con la temática, pero en ningún modo impuestas por ella, influyen en otros parámetros muy ligados entre sí: decrece el promedio de palabras por página ( $a 334$ / b 334 / c 309); este cuaderno, por fin, es el que emplea la cantidad más elevada de guiones (93, promedio de los cuads. $a-h$ 70,4).

En resumidas cuentas, en $c$ compiten dos tendencias opuestas: ahorrar espacio para compensar el probable desbordamiento del libro I con respecto a las previsiones del que preparó el texto (es muy probable que se planeara una coincidencia exacta entre el final del libro y el último cuaderno de $b$ ), y por otra parte adaptar la presentación del texto a la especificad del nuevo tema, y sobre todo de su ejemplificación (versos ya, no palabras aisladas).

\subsubsection{Cuaderno d (25r-32v, II.8-III.4, prosodia, etimología y dicción)}

Esta preocupación sigue manifestándose en el principio del cuaderno $d$ (después de 10 citas poéticas fuera de texto en $23 r-24 r$ otras 15 se hacinan en 25r-28r) y hasta va menguando la presión gráfica en el folio inicial, que no alcanza las 250 palabras por página (p. g. 301). En realidad, este cuaderno consta de dos mitades muy diferentes, que corresponden respectivamente al final del libro II sobre prosodia (25r-28v) y a los capítulos 1-4 del libro III que tratan del nombre.

Cuadro 2. Cuaderno d. Contraste entre los libros II y III

\begin{tabular}{|c|c|c|}
\hline Fenómeno & $25 r-28 v$ & $29 r-32 v$ \\
\hline Palabras & 2223 & 2456 \\
\hline Blancos & 3697 & 2272 \\
\hline Abreviaturas & 76 & 257 \\
\hline Signos restituidos & 107 & 304 \\
\hline Puntos & 206 & 330 \\
\hline
\end{tabular}

En el final del libro II ya no se añade ningún comentario a continuación de un verso corto (comp. cita arriba):

Hijo mio mucho amado

Para mientes. (25r3) 
Inmediatamente, decrece el número de palabras y de abreviaturas y se incrementa el de los espacios, que de vez en cuando rebaja la media de la parte B, 483 (25r 676, 25v 560). El incunable se aproxima al libro moderno y la tipografía resalta con mucha eficacia los principales componentes del discurso gramatical: descripción o/y definición, ejemplificación, comentario (24v3225r19). En el libro III, el discurso, al reanudar con la exposición metódica, vuelve a hacerse más denso, repleto de enumeraciones (partes de la oración 29r8-21, accidentes del nombre 29r31), de ejemplos y comentarios didácticos («Antecedente se llama: porque se pone delante del re-/lativo» 30r32). La variación del cuadro 2 refleja los cambios en la temática. Esta inversión del proceso anterior ya se advierte en el folio $28 \mathrm{v}$, último del libro II: ningún párrafo externo, espacios en baja, 2P muy por encima de la media del cuaderno. El doble cariz del cuaderno $d$ es lo que mantiene a un alto nivel la densidad propia de la primera parte y se refuerza todavía en el cuaderno $e$.

\subsubsection{Cuaderno e (33r-40v, III.4-12, partes de la oración)}

En muchos aspectos $e$ compite con $a$ y $b$, cuando no rebasa las tasas ya reseñadas. Le corresponde el rango 1 en lo que atañe al número de abreviaturas por página (42, y hasta 100 en $55 \mathrm{v}-3$ por línea-), lo cual en seguida denota un evidente exceso de letras, confirmado por la frecuente ausencia de marca en el corte de las palabras (14 guiones olvidados en 34r y 37r — sólo se observan semejantes desvíos en los cuadernos $c$ y $d, 24 \mathrm{v}$ y $30 \mathrm{v}-)$, y el número de signos tipográficos por página (inmediatamente después de $b$ ). Asimismo, sigue a $b$ en la economía de blancos (b 282 / e 296). Esta doble marca de signo opuesto expresa algunas peculiaridades del método didáctico de Nebrija, repetición de las fórmulas introductorias y enumeración de las distintas modalidades de un fenómeno, cada vez ejemplificadas y realzadas por puntos: «Otros [nombres verbales] salen en.ura.como de andar andadura.» 33v1... En 35r (258 blancos, 88 puntos - p. g. para A 45-) se manifiesta con especial relieve la propensión a definir minuciosamente los objetos gramaticales cuyas distintas clases se han de inventariar a continuación:

$\mathrm{Nu} / \mathrm{mero}$ enel nombre es aquello por que se distingue uno de mu/chos. El numero que significa uno llamase singular.co/mo el ombre.la muger. El numero que significa mu-/chos llamase plural.como los ombres.las mugeres. (35r6)

Y en 36r (la página que menos blancos utiliza en la GC, 207 - con 88 puntos-), vuelven a aparecer la presentación por oposición ( $c f r .8 v 13,11 v 18$ ) y la proclividad (¿medieval?) a la lista exuberante de ejemplos, como en el libro II (cfr. 20v-21r): 
Delas cosas secas que se miden $\tau$ / pesan algunas tienen singular $\tau$ no plural. como trigo./ cevada. [...]. J por el contrario otras tienen plural $\tau$ no/ singular.como garvanços.havas. [...] (36r9)

Otro rasgo específico de la parte A que en $e$ encuentra su mejor exponente: la tasa de párrafos internos alcanza en este cuaderno su nivel más alto (5,2 por pág. / p. g. 3,4) y permite localizar algunos pasajes particularmente significativos en lo que respecta a la estructuración y recursos didácticos del tratado; p. ej. en 36v (8) se definen y enumeran las características de los pronombres:

Los acci/dentes del pronombre son seis. [...]

Las especies / del pronombre son dos [...].

Las figuras del pro/nombre son dos. [...];

cada característica se introduce tras un párrafo interno, siguiéndole varios ejemplos.

Así es como la tipografía, en sus múltiples aspectos, va dando forma y relieve al proyecto didáctico. No sólo lo estructura de tal modo que el lector pueda aprehender con comodidad todas las articulaciones de la exposición, sino que facilita la búsqueda independientemente de la lectura, propiciando además la memorización del contenido. La repetición de los mismos esquemas materiales como [P Bi M] 'punto', 'blanco(s)', 'mayúscula', es una ayuda inmejorable para seguir paso a paso el desarrollo del tratado. Por otro lado, en un contexto general de densidad gráfica, la técnica del impresor consigue, a pesar de algunos fallos y a través de unos atajos o escorzos de emergencia (faltas de espacios, guiones, puntuación), encaminar al lector hacia una percepción clarificadora y hasta razonada del texto.

En la segunda parte del libro, cambian globalmente las perspectivas, pero la evolución general, dependiente como siempre de la temática, no es uniforme ni regular.

\subsection{Parte B}

4.2.1. Cuaderno f (41r-48v, III.12-IV.4, partes de la oración, morfología y sintaxis)

Aunque el libro III acaba en 45r, el cuaderno $f(41 \mathrm{r}-48 \mathrm{v})$ presenta todas las señas de una ruptura con los anteriores. Va disminuyendo en todos los aspectos la densidad tipográfica: la cantidad de palabras pasa de 323 por página $(e)$ a sólo 270, y paralelamente casi se desploman otros valores como el número de signos tipográficos (e 1462 / $f$ 1267), de abreviaturas (42 / 12) o de párrafos in- 
ternos $(5,2$ / 1,9). Por el contrario, sube de repente el número de espacios (que alcanza el total hasta aquí desconocido de 479 casos por página, lo que destaca este cuaderno como el que más espacios tiene después de $h, 607$ —promedio de la parte A, 317-) y también supera el uso de las mayúsculas al promedio de A (12/16).

Esta nueva orientación general coincide con nuevas perspectivas a nivel editorial: casi se duplica el total de líneas blancas en la parte B (A 8 / B 14) (verdadero lujo tipográfico en esa época temprana de la imprenta); también se hace absolutamente regular la mención del nuevo capítulo en línea aparte y se aleja del margen izquierdo la misma palabra «Capitulo» mediante un espacio variable pero equivalente muchas veces a tres o cuatro espacios (comp. 46v22 con $34 \mathrm{r} 23$ en $e$ ). El decrecimiento de la tensión gráfica permite otro tratamiento de contenidos muy similares. En 33v se citan sin interrupción y con minúsculas los ejemplos de nombres verbales que corresponden a los distintos modelos del inventario. En 44r los adverbios vienen presentados en líneas diferentes y empieza cada una con mayúscula (sin sangría), terminando con punto:

De lugar como aqui.ai.alli.

De tiempo como aier.oi.mañana.

Lo mismo se observa en $47 \mathrm{r}$ con la relación de los verbos, clasificados según su régimen:

Recuerdo me de ti.

Olvido me de dios. (47r6)

o en $41 v$ con una lista de participios. Este cambio espectacular en la disposición del texto supone una profunda modificación en el aspecto visual. La cita de ejemplos fuera de texto no sólo provoca un uso inhabitual de mayúsculas ( 27 en 44r, 28 en 47r / p. g. 14), sino que incrementa en extremo el valor ilustrativo de cada ejemplo («Plaze me leer» 47v22), como si se quisiera estamparlo por separado en la memoria gramatical del lector.

La mayoría de estos cambios aparecen ya en el final del libro III, aunque sigue idéntico el método expositivo. Pero a pesar de esta continuidad discursiva, el libro, en cuanto imagen física del texto, presenta un conjunto de cambios sustanciales, que se van a reforzar en los cuadernos finales. En el marco de esta evolución general se produce sin embargo una doble ruptura temática (sintaxis / figuras, libro IV / nuevo prólogo), y por otro lado una serie de desajustes y novedades. 


\subsubsection{Cuaderno g (49r-56v, IV.4-V.2)}

¿Interrupción en la composición del texto o innovación en el tratamiento de los ejemplos?, ¿cambio de cajista, descuido, o elección deliberada?, es patente el contraste entre el comienzo del ejemplo que se cita en $48 \mathrm{v} 34$ y los tres renglones que se añaden al principio del cuaderno $g$ (49r3):

[como diziendo] io compre un negro. //

Crespo los cabellos.

Blanco los dientes.

Hinchado los beços.

Según el uso general en la $G C$, «como diziendo» (98 casos) introduce directamente el ejemplo que se suele aducir tras una definición o una afirmación teórica: «como dizi[e]ndo / un ombre vino». (36v4); «io compre un negro» forma parte, pues, del ejemplo que se anuncia y, según el nuevo canon tipográfico, tenía que presentarse en el renglón siguiente (lo que además permitía citar en 49r, primer folio del nuevo cuaderno, el ejemplo entero). Al parecer, el cajista (acaso el propio Nebrija) distinguió, no obstante, el primer segmento, simple soporte del verdadero ejemplo, y los tres elementos finales, citados como tres ejemplos del fenómeno denominado «sinedoche» (49r4). Efectivamente, el primer elemento no contiene ninguna sinécdoque, y por otra parte, cuando presenta esta figura en la relación de los metaplasmos (51v3), Nebrija repite casi el mismo ejemplo: «como diziendo el / guineo blanco los dientes:se enfria los pies», en el que «el guineo» también es soporte (contorno) del segmento determinante que le sigue, el ejemplo propiamente dicho.

Quizá pueda interpretarse la desmembración del ejemplo como la combinación, eficaz pedagógicamente, de dos métodos para presentar los ejemplos: el que domina en la parte A (el ejemplo es parte integrante del enunciado) y el que domina en la parte B (el ejemplo se pone de realce mediante una suspensión del discurso y recurriendo a un sistema de tres marcas gráficas, punto y aparte, mayúscula inicial, resto de la línea en blanco). Desde esta perspectiva, los primeros renglones de $g$ confirmarían la profunda mutación que se observó en $f$ relativamente al tratamiento de los ejemplos. Hay más: en estos mismos renglones coinciden tres eventos, uno vinculado a la temática gramatical, otros dos a la técnica tipográfica. En 49r4 («Esta figura los grammaticos llaman sinedoche»), es la primera vez que se emplea el término figura en relación con la sintaxis. Antes, en la $G C$, pertenece bien al campo de la ortografía («figura de letra» 8r1), o de la fonética («figura dela boca»9r10, «omeoptoton» 23r16, etc.), bien al de la morfología («emphasi» 36v26). Esta mención, que concluye el capítulo 4, anuncia explícitamente el contenido de lo que va a seguir hasta el 
final del libro IV (49r4), salvo que no todos los metaplasmos que se examinarán en los capítulos 6-7 serán figuras sintácticas. Pero tampoco interesan a la sintaxis (tema del libro IV), los dos primeros apartados del capítulo 5, que versan sobre el barbarismo. Cualquiera que sea la importancia intrínseca del estudio del barbarismo y las figuras como prolongación del libro III, supone, con respecto a la sintaxis, una multitud de desvíos ${ }^{20}$. No se aborda la sintaxis de ocho de las diez partes de la oración; el barbarismo y el solecismo sólo describen los vicios en el habla, no la «acostumbrada manera de hablar» (49v25); algunas figuras no son «vicio incomportable» (50v27), sino que «se puede[n] escusar por alguna razon»; muchas de ellas, por último, se circunscriben a la palabra y sólo afectan a su realización fonética — «Apocopa» 50r19, «Sincopa» 50r12... - o a su morfología («Prosthesis» 49v31, «Epenthesis» 50r8) ${ }^{21}$.

Exactamente en el mismo espacio del folio 49r aparecen dos fenómenos tipográficos nuevos: en 49r4 se utiliza por primera vez el alógrafo $\langle\varsigma\rangle$ de $\langle$ s $>$ («gramaticos») (que se asemeja a la sigma final griega), y por otra parte, en 49r8 se documenta el primer ejemplo de letra provisional en el hueco que se deja al principio del capítulo para la mayúscula inicial.

La grafía con $\langle\varsigma\rangle$ en espiral o estirada es privativa de los últimos cuadernos, pero domina en $g(53 / 27 / 5)$. La $G C$, en conformidad con los usos de la época, suele emplear básicamente la $<\mathrm{s}>$ de doble curva (la moderna) y la alta o larga (casi idéntica a una $<\mathrm{f}>$ sin raya). Cuando se componen el cuaderno $g$ y siguientes, es de suponer que acabarían de devolver a los cajetines los tipos correspondientes a otro texto y los usaría el cajista, sin que le importara la mezcla de variantes. El caso es que también en el Lexicón (coetáneo) y el Vocabulario (posterior) se usa este tercer alógrafo de $<\mathrm{s}>$. En la $G C$, se encuentra casi siempre en posición final, pero una vez se registra en posición inicial («らon» 57r10), lo que no ocurre, al parecer, en el Lexicón ni en el Vocabulario donde sólo ocupa la posición final de palabra (Lex «galtero̧» 2r2:30, Vocab «onras» 2r1:3) o de sílaba (Lex «Ariçba» 22v2:19, «Vocab» «decbaratar» 2v1:1). Aunque pueden encontrarse las tres soluciones en algunos manuscritos, como es el caso en el ms. Esc. h.III.9 de Calila e Dimna según Riesco Terrero

${ }^{20}$ Cabe subrayar en la elección nebrisense el influjo del Ars maior de Donato, que también dedica su parte final a los vitia orationis (barbarismo, solecismo, figuras y tropos) - vid. Carmen Codoñer, «Las Introductiones latina de Nebrija: tradición e innovación», en V. García de la Concha, ed., Nebrija y la introducción del Renacimiento en España, Salamanca, Universidad de Salamanca, 1983, págs. 105-122_; pero estos capítulos de la $G C$ no son más que una refundición de los fols. $46 \mathrm{v}$ y sigs. de las $I L$.

${ }^{21}$ Nebrija reúne en el cap. 6 («Del metaplasmo») gran parte de los fenómenos que conciernen a la palabra considerada aisladamente, pero no cabe duda de que para él esos metaplasmos son verdaderas figuras, ya que titula el cap. 7 «delas otras figuras». Aunque éstas implican, por lo común, la presencia de dos palabras, cuando no un enunciado más extenso, algunas de ellas sólo registran un fenómeno fonético muy restringido («Paromeon» 53r14). 
(1995: 182b $)^{22}$, su total ausencia en los primeros seis cuadernos indicaría más bien en la $G C$ una variación meramente tipográfica, debida a circunstancias particulares; presenta, sin embargo, un evidente interés para la historia de la escritura ya que los tres alógrafos se emplean según una distribución que ni es totalmente aleatoria ni tampoco enteramente complementaria (no se duplica la $<\varsigma>$, rara vez se usa en posición inicial, no aparece la $<\mathrm{s}>$ larga en posición (inal $)^{23}$.

En lo que se refiere a la inicial capitular, el hueco que coincide con las primeras líneas de cada capítulo no lleva ninguna minúscula hasta el principio de $g$, pero en adelante los nuevos capítulos siempre ofrecerán esta letra de aviso, excepto en 59r33 (cap. V.4, h). Desde un enfoque histórico, la falta de minúscula provisional corresponde a una etapa anterior del libro impreso (Martín Abad, 2004, p. 91) $)^{24}$; la $G C$ documentaría, por consiguiente, dos etapas consecutivas de la disposición textual; pero cabe resaltar que en ningún caso intervino un iluminador para añadir la capitular que faltaba; asimismo quedaron vacíos (o sea sin calderones) los segmentos en blanco de los párrafos internos que a veces preceden a mayúscula. Este aspecto de relativo desaliño, de producto sin acabar, evidencia el carácter utilitario de la $G C$.

La novedad más atractiva de $g$ la constituye el uso casi generalizado y libre del párrafo en la presentación del barbarismo, el solecismo y las figuras de retórica (49r-55r). En la parte A, cuando el texto pasa a la línea, lo que por lo común disimulan las apariencias son párrafos internos cuya señal identificadora (el espacio de dos o varias letras en blanco) se desplaza al principio del renglón siguiente por no quedar bastante espacio al final del renglón anterior (10v27, $14 \mathrm{v} 27,14 \mathrm{v} 30)$. El resultado tiene exactamente el mismo perfil que un paso a la línea con sangrado; pero el contexto general y el uso tipográfico demuestran claramente que no es así $(14 \mathrm{v}, 15 \mathrm{v})$. Para que asome un auténtico párrafo, el requisito mínimo es la presencia de un segmento en blanco superior al que separa dos enunciados (delimitado por punto y mayúscula); en $g$ se suman los dos rasgos modernos que identifican al párrafo, paso a la línea y sangrado:

\footnotetext{
22 Ángel Riesco Terrero, Elisa Ruiz García, Jesús Domínguez Aparicio y Ana Belén Sánchez Prieto, Aproximación a la cultura escrita, Madrid, Playor, 1995, 237 págs. (Textos y recuperación).

23 Otras precisiones: en las listas de letras (12 casos) sólo se usa una vez la $<\mathrm{s}>$ de doble curva (16v11); es casi general, pues, la $<\mathrm{s}>$ alta; se observa la misma tendencia en la $<\mathrm{s}>$ aislada, si bien aumenta la fluctuación $(5<\mathrm{s}>$ altas $/ 3<\mathrm{s}>$ de doble curva: 14r5, 17v1 bis). Todos los ejemplos de $<\mathrm{s}>$ moderna se localizan en los cuadernos $b$ y $c$, pero estos cuadernos también emplean el otro alógrafo para notar la letra.

${ }^{24}$ Julián Martín Abad, Los Libros impresos antiguos, Valladolid, Universidad de Valladolid, Secretariado de Publicaciones e Intercambio Editorial, 2004, 160 págs. (Acceso al saber. Serie Libro y Literatura; 2).
} 
entre solecismo $\tau$ phrasis esta schema.

Barbarismo es vicio no tolerable [...] (49r21)

Esta disposición, que asigna a cada figura el espacio textual de un párrafo entero, mejora en alto grado la eficacia pedagógica de la exposición, al tiempo que facilita la consulta selectiva del tratado, cuya presentación lo asemeja a un léxico técnico, elaborado a base de artículos encadenados, si bien no se conforma con el orden alfabético («Sinalepha» 50v9, «Ectlisis» 50v14, «Antithesis» 50v20). Tampoco resulta perfectamente regular la delineación de los párrafos. De vez en cuando se omite el paso a la línea («Synecdoche» 51v3, «Paronomasia» 53r6), lo que supone un regreso hacia el párrafo interno. Puede olvidarse también la sangría («Apheresis» 50r3, «Paragoge» 50r15). Incluso en ocasiones se citan versos a línea tirada $(52 \mathrm{r} 16,52 \mathrm{r} 22)$, aunque suelen ir fuera de texto (50r31, 52v21). No son nada extrañas estas vacilaciones en una época en la que la imprenta todavía está buscando modelos propios frente a la tradición manuscrita. Con la ayuda de un análisis fundamentalmente enumerativo, la exposición del libro IV sigue presentando hasta el final (55r) las mencionadas características, que por otra parte coinciden con un esquema discursivo muy reiterativo: para cada figura (citada de manera autonímica como cabeza de párrafo), definición, ejemplificación y síntesis ${ }^{25}$.

Aunque el principio del libro V (presencia de un prólogo, resumen doctrinal del capitulo 1) favorece la condensación del discurso y de la materia gráfica, se observa a continuación, y en toda la parte final de la $G C$, una pronunciada tendencia a usar el auténtico párrafo, lo que, sin duda alguna, le da al tratado un aspecto globalmente mucho más moderno que en la parte A, más cercana a la tradición.

\subsubsection{Cuaderno h (57r-64v, V.2-6, declinaciones, conjugaciones, modo indica- tivo)}

A pesar de esta reorientación general en la disposición linguiística y tipográfica, el cuaderno $h$ ostenta una personalidad muy marcada en distintos planos.

\footnotetext{
${ }^{25}$ Se notará además que la fórmula introductoria [X es cuando] se repite sin cambiar; en este particular, Nebrija se conforma estrictamente con la tradición (comp. A. de Palencia, UV, passim [p. ej. 437vb-438rb], que ya reproduce a Papías, o las Etimologías de Isidoro, herederas del Ars maior de Donato - para esta transmisión, vid. Juan Casas Rigall, entre otros estudios «Ad grammaticos pertinent. La teoría de los vicios, figuras y tropos en diez gramáticas hispanas del siglo XV», La corónica, 24/2, 1996, págs. 78-102, «Retórica y diccionarios: vitia gramaticales, figuras y tropos en el Universal Vocabulario de Alonso Fernández de Palencia», La coronica, 34/2, 2006, págs. 203-226, «Vicios gramaticales y licencias oratorias: un capítulo deturpado de la Gramática de Nebrija», Neophilologus, vol. 81, 1997, págs. 539-549-).
} 
En seguida se nota un nuevo desajuste en la linde de los cuadernos (56v / 57r), al invertirse la presentación respectiva del número (sing. / plur.) y de los casos: en $g$ se indica mediante una sangría «Enel numero de uno» (56v24-25), mientras que se ajusta al margen izquierdo la mención de caso; en $h$ se ajusta al margen la mención de número, escribiéndose con sangría la de caso (57r3-4 y sigs.). Esta ruptura puede reflejar un cambio de cajista o una suspensión suficiente en la composición para explicar que se olvidara el esquema anterior. De todas formas, resaltan concretamente la autonomía de los cuadernos y la variación en las opciones técnicas a lo largo de un libro.

Otra novedad muy interesante: cada caso de las declinaciones viene presentado como un ejemplo distinto (punto y aparte, mayúscula, punto final —con muy pocos olvidos, 56v26-, alineación de los casos, sin sangría — primeroo con ella —en $57 \mathrm{r}$ - ). En cambio, mención de caso y ejemplo van yuxtapuestos sin puntuación; el punto sólo aparece, con intermitencia, entre las variantes del ejemplo, si las hay («el.la.lo.» 59r18 / «este esta esto.»58v22). La formulación de cada caso prolonga otra vez la tradición medieval de las grammaticae proverbiandi en su vertiente práctica ${ }^{26} \mathrm{y}$, en cierto modo, la de las preguntas y respuestas (erotemata). Sobresale en estas nóminas la preocupación didáctica de Nebrija; más que el resto del texto, los ejemplos son paradigmas que los alumnos tienen que aprender de memoria. La repetición de los modelos expresa también la importancia de determinadas prácticas orales en el aprendizaje de un idioma (incluso en la memorización correcta del propio idioma).

Por otra parte, puesto que el castellano no tiene casos (35r11, véase arriba, $\S 2$ ), en el libro $\mathrm{V}$ lo que en realidad se enumera son las construcciones castellanas que se corresponden con los casos latinos. Lo único que pueda servirle al lector es el etiquetado metalingüístico que estructura la exposición: «nombre» (56r33, 56v16...) / «Adjectivo» (57r28) / «Relativo» (57v20), puesto que no cambia nunca el final de la palabra (sólo alternan singular y plural); lo que sí cambia es lo que antecede (artículo / $\varnothing$ artículo, de SN / $a \mathrm{SN} / \varnothing \mathrm{SN}$ ), o sea el entorno sintáctico.

A este respecto, contrastan fuertemente con los caps. 2-3 los dos siguientes (conjugaciones de los verbos), porque en las conjugaciones, para cada tiempo es diferente la forma de cada persona, y por tanto relevante la presentación por modos, tiempos y personas. La unidad que cabe memorizar ya no es el sintagma con su rección («del cielo.», «al cielo.» 57r5-6), sino una palabra, con su flexión particular, en el marco más amplio de un tiempo determinado («Amo.amas.ama.amamos.amais. aman» 59v21). Se vuelve a usar, por consiguiente, el mismo sistema de puntuación que en las enumeraciones de palabras de los libros II (20v) ó III (54r14), el de los puntos-comas, que se añaden a los

\footnotetext{
${ }^{26}$ Vid. Calvo Fernández, Grammatica Proverbiandi..., cit., pág. 41.
} 
puntos finales de cada renglón. De ahí una proliferación excepcional de puntos (88 por pág.), y como se normaliza la presentación de casos y tiempos, también de mayúsculas (26).

Cabe recordar, a este respecto, que en $h$ (60r-62r) se ensancha la caja de escritura para presentar en el mismo renglón las seis personas de un mismo tiempo (a veces sólo las primeras cuatro en los tiempos compuestos). Así es como se alcanzan en dos ocasiones las cuotas más altas de signos tipográficos por página $(60 \mathrm{r} 1585,61 \mathrm{v} 1586)$, a poca distancia de las páginas de menor densidad de todo el texto (57r 718 — declinación del nombre-, 58v 589 —declinación del pronombre-). No es nada imposible que interviniera el propio Nebrija para que a cada paradigma (amar, leer, oír...) se le dedicara una línea aparte, al ver cómo recurre el cajista a las abreviaturas más insólitas, tanto en el pasaje de líneas largas («ovieron am.»60r15, «avian a.»60r27, «oviessemos am» — sin punto- 61v32) como en las páginas con línea normal («aver leido. aver oido. aver sido. aver aui/-do» $62 \mathrm{v} 1$, con $\langle\mathrm{v}>$ puntuada y el segmento cortado $<-$ do $>$ al final del renglón siguiente).

Pero la acumulación enumerativa de las conjugaciones no produce el mismo efecto que la ejemplificación exuberante en la parte A porque las líneas pletóricas alternan con las líneas breves, de modo que al fin y al cabo el cuaderno $h$ es el que menos palabras tiene por página (257) y el que más espacios utiliza (607). Explica esta aparente paradoja el que, en las declinaciones cada caso, en las conjugaciones cada tiempo venga tratado como un párrafo. Por eso se registran tan pocos guiones (2 por pág.), olvidos de guión (3), abreviaturas ( 9 - la tasa más baja en la $G C$ - / p. g. 25), 2P (1) o párrafos internos $(1,4)$. En cambio, abundan más que en cualquier otro cuaderno los párrafos externos $(9,9 /$ p. g. 6,5), lo que le confiere al cuaderno $h$ un estatus específico.

Otra vez (como en $d$, pero sin que se opongan dos libros distintos) se observa una patente asimetría entre las páginas que se dedican a las declinaciones y conjugaciones (dos tipos de ejemplos fuera de texto) y la exposición que sigue (que incorpora los ejemplos al texto).

Cuadro 3. Contraste entre principio y final del cuaderno $\mathrm{h}$

\begin{tabular}{|c|c|c|c|c|c|}
\hline Fenómeno & $57 r-62 v$ & Promedio/pág. & $63 r-64 v$ & Promedio/pág. & P. g/cuad. \\
\hline Blancos & 8514 & 710 & 1195 & 299 & 607 \\
\hline Palabras & 2792 & 233 & 1317 & 329 & 257 \\
\hline Abreviaturas & 81 & 7 & 57 & 14 & 9 \\
\hline Puntos & 1106 & 92 & 303 & 76 & 88 \\
\hline
\end{tabular}


Los valores del último cuarto del cuaderno no sólo expresan una oposición palmaria con los de la primera parte y los del cuaderno entero; dos de ellos rebasan los promedios de la primera parte de la GC: menos blancos (317 / 299), más palabras (318 / 329); la evolución general de B se verifica, sin embargo, en el uso de las abreviaturas (A $31 / 14$ ), y los puntos (A 45 / 76). Concuerdan la merma de los blancos y la reducción de las abreviaturas, el aumento de puntos y el crecimiento del número de palabras; este fenómeno tendrá su origen en la ejemplificación. Los fols. 63-64 ejemplifican sistemáticamente cada nueva especificación, repartiendo los ejemplos entre morfemas que aparecen en las definiciones ( $\tau$ forma se del presente del infinitivo mudan-/do la. er. [sic] final en.i.» 64v15), y formas verbales que ilustran la clase que se acaba de describir («como de leer lei. de correr corri.»64v16). Si los segundos son auténticas palabras, los primeros, monosilábicos siempre, inducen, con una densidad de signos tipográficos por página muy próxima a la de la parte $\mathrm{A}$, una cantidad de palabras ligeramente superior, lo que recalca la afinidad de los últimos folios de $h$ con la parte A desde distintos puntos de vista (método expositivo, realización gráfica).

\subsubsection{Cuaderno i (65r-67v, V.6-11, otros modos verbales)}

En este último cuaderno de la $G C$ el texto sólo ocupa tres folios. Sigue afirmándose la evolución general de $\mathrm{B}$ hacia una presentación más flexible y holgada, como muestra la presencia, en tan breve espacio, de 3 líneas blancas entre título de capítulo y texto $(65 \mathrm{r} 22,66 \mathrm{v} 11,66 \mathrm{r} 21)$. De mantenerse el mismo ritmo a lo largo de 16 páginas, $i$ alcanzaría un total de 9 líneas en blanco, casi la mitad de las líneas documentadas en toda la $G C$ (22); sólo $b$ (entero) ostenta tantos espacios entre título y texto. Se notará de paso que $f$ (el cuaderno que más líneas blancas tiene, 6) da la preferencia a la línea que antecede a la mención de libro o capítulo (43v24, 44v33, 45r31, 46r15), mientras que en $i$ la línea se introduce tras la mención de capítulo y el título (que ambos caben en el mismo renglón). Pervive, sin embargo, el reflejo tradicional de colocar la mención de capítulo en el renglón que sigue al final del capítulo anterior (si bien con punto y aparte), e incluso, una vez, en el espacio vacío del último renglón (67r22). Las demás características de $i$ lo acercan al cuaderno $h$ en lo que atañe al uso de abreviaturas $(9$, como $h)$, o de $2 \mathrm{P}(1$, como $h)$, lo que significa que la densidad tipográfica no impone escorzos, y el enunciado deja de integrar miembros concatenados.

En realidad, el estilo declarativo y el perfil metódico de la exposición orientan al alza algunos parámetros, si bien se mantiene una notable distancia con respecto a los promedios del texto entero. Así es como $i$ emplea más pala- 
bras por página que el promedio de B (292 / 277) y, consecuentemente, menos blancos (407 / 483). Estos datos resaltan el carácter más homogéneo del texto, en el que la integración de los ejemplos en los enunciados descarta muchos espacios potenciales, mientras se alarga el mismo enunciado, como indican, por un lado la reducción del número de párrafos externos y de mayúsculas, por otro el ligero crecimiento del número de párrafos internos $(1,8 / \mathrm{p}$. B 1,6). Se evidencia la importancia de los cambios tipográficos y la evolución en la disposición general del texto al comparar los valores de $i$ con los promedios de la parte A:

Cuadro 4. Cuaderno i. Contraste con la parte A de la $\mathrm{GC}$ (valores por página)

\begin{tabular}{|c|c|c|}
\hline Fenómeno & promedio A & cuaderno $\mathrm{i}$ \\
\hline Palabras & 318 & 292 \\
\hline Blancos & 317 & 407 \\
\hline Abreviaturas & 31 & 9 \\
\hline Puntos & 45 & 58 \\
\hline Dos puntos & 12 & 1 \\
\hline Párrafos externos & 1,7 & 3,8 \\
\hline Párrafos internos & 4,6 & 1,8 \\
\hline
\end{tabular}

Todos estos valores indican una disminución significativa de la tensión tipográfica que caracteriza a la parte A. En el discurso didáctico casi desaparece la articulación interna del enunciado que señalan los $2 \mathrm{P}$; por otra parte, se extiende cada vez más el esquema del párrafo externo, a expensas del párrafo interno. Poco a poco se va haciendo más perceptible desde fuera la composición del tratado. Pero si el ordenamiento del discurso puede atribuirse con toda probabilidad (o en la mayoría de los casos) al autor, la presentación depende mucho, acaso mucho más del impresor, y en la repartición de las unidades discursivas se observa hasta el final una constante vacilación entre soluciones concurrentes, en particular entre párrafo externo y párrafo interno en una descripción enumerativa: en $66 \mathrm{v}$ se elige la primera opción para «/El passado acabado» (66v10), la segunda para «El passado mas que acabado» (66v13)... Es posible que no se trate únicamente de fluctuaciones de imprenta; la prosa de la época, al parecer, no había estabilizado todavía la representación gráfica de sus modelos discursivos (por ser aún mal definido el concepto de párrafo).

Pero el estudio de estos temas, en lo que se refiere a la $G C$, exige un análisis globalizador de todas las articulaciones que configuran el tratado (libros, capítulos, enunciados, párrafos, etc.). Será el objeto de un artículo posterior. La nueva lectura de la $G C$ que se realizó a través de su tipografía, y básicamente 
a partir de los cuadernos, ya permite defender un punto de vista que no se suele tomar en cuenta, pese a que la disposición material del incunable constituya un aspecto fundamental del significante que se quiere interpretar.

\section{EL TEXTO Y SU REPRESENTACIÓN GRÁFICA}

Más allá de las circunstancias que originaron las diferencias entre las partes A y B del libro (errores de cómputo, cambios de cajista, etc.), el examen de los cuadernos pone de manifiesto una serie de rasgos específicos en la concepción didáctica y la elaboración tipográfica del tratado que, en el mejor de los casos, pueden distinguirse pero nunca deben separarse. Si la parte A es más densa, maciza, no se debe únicamente a que se equivocara en sus previsiones el que preparó el texto para la imprenta, sino a una multitud de opciones pedagógicas en la concepción del tratado: exposición metódica, con divisiones jerárquicamente ordenadas, explicaciones y ejemplos. Pero la tipografía aporta al texto una forma legible determinada (que pudo ser muy distinta, como demuestra la variación en las opciones), dispone áncoras aprovechables para una posible lectura en voz alta ante un público escolar, y selecciona poco a poco un conjunto de metasignos cuya función es llamar la atención del lector sobre las articulaciones del discurso gramatical.

Estos metasignos pueden ser externos o internos, simbólicos o léxicos. Internos y léxicos como el anuncio del primer Prólogo ( $\tau \tau$ pone primero el prologo» 2r5), como la ordenación explícita de las diversas clases de un fenómeno: «Otros tres acentos tiene/ nuestra lengua [...]. El primero de agudo $\tau$ grave []. / El segundo [...]» (18v31). Externos como las divisiones en libros y capítulos, que actualizan distintas marcas: el calderón, heredado del manuscrito ( 2 veces), para señalar el comienzo de libro en 5 r1 o de capítulo en 7r33, la unidad léxica correspondiente («Libro», «Capitulo») con mayúscula inicial y número de identificación, un título que sintetiza la temática de la nueva división, y una disposición particular en el espacio de la página. Cada uno de estos elementos admite una variación: calderón/ $\varnothing$, «Capitulo segundo» 5v12/ «Capitulo.iij.» 7r33 / «Capitulo.x.» 16v33/ «Capitulo.v.»62v10... A este respecto se observa a lo largo de los cuadernos una patente evolución hacia una presentación más cercana a la presentación moderna, en la que la mención de capítulo tiende a ocupar una línea distinta con sangrado.

Pueden también considerarse metasignos de primera categoría en la escritura de molde los espacios de todo tipo que estructuran el discurso y orientan la lectura. El espacio inicial es la marca más vistosa que destaca el comienzo de un libro o de un capítulo. En algunas ocasiones (11v11, 28v31) puede extenderse al renglón completo. Alguna vez, también separa un título del texto 
(11v14, 27v31). Esta marca, muy costosa, y excepcional en un libro utilitario como la $G C$, aparece con mayor frecuencia en la parte B. Metasigno también, el hueco que se deja para la inicial capitular, presente en todos los capítulos, revela una constante en la técnica tipográfica, si bien varían el tamaño del hueco y su apariencia. Dicho espacio, que queda vacío hasta el cuaderno $g$, tenía para el lector una función parecida a la de un calderón y completaba el sistema de marcas que indicaba las principales divisiones del texto.

De particular interés también para él, el espacio más limitado que separa los enunciados, desde la supresión tras punto («ombre.El segundo» 35v9...) hasta la dilatación que señala un párrafo interno (hasta 22 signos ante «Estos dos» 62v32). El examen de los cuadernos mostró que entre el principio y el final del texto se extendía el empleo del párrafo externo, a expensas del párrafo interno (procedimiento tradicional, con la inserción de un calderón, para señalar una pausa o una articulación importante del discurso). En realidad, el párrafo externo es el nivel intermedio entre capítulo y enunciado y, en la época de Nebrija, todavía representaba una modalidad especial de párrafo interno, salvo que al amplio espacio en blanco se añadía el paso a la línea, en general sin sangrado (26v28, 31v3). Por lo tanto, la intensificación del uso del párrafo externo indica una profunda ruptura en la representación del contenido didáctico, lo mismo que otros cambios (menos $2 \mathrm{P}$, más capitales, etc.). No se trata de un puro artefacto del impresor, sino que va modificándose a lo largo del texto el estilo expositivo del gramático, que tiende a acortar los períodos y recurrir al módulo párrafo como a una entidad textual autónoma y consciente (véase IV.6-7, 56v, o 58r).

La ambigüedad habitual del párrafo se manifiesta de diversas maneras. La mención de capítulo aparece a veces como último segmento del renglón final del capítulo anterior, según un esquema [texto, espacio, Cap.]. Se trata de una de las variantes del párrafo interno. A la vista de lo que antecede, no es ninguna casualidad que ocho ejemplos de este fenómeno se encuentren en la parte A, y sólo dos en la B. Otra modalidad de párrafo interno que poco a poco se convierte en auténtico párrafo externo es la cita de versos fuera de texto (23r...) y luego la cita de ejemplos que se observa a partir del cuaderno $f(41 \mathrm{v}, 44 \mathrm{r})$.

No existe una radical diferencia entre el párrafo y el enunciado, si bien el párrafo externo reúne a veces varios enunciados. Sirven en ambos casos los mismos signos básicos, la tríade punto, espacio, mayúscula, por cierto con variantes: [P B $i \mathrm{M}],[\mathrm{B} i \mathrm{M}],[\mathrm{P} \mathrm{B} i / \mathrm{M}],[\emptyset \mathrm{P} /(\mathrm{B} i) \mathrm{M}]$. Estos modelos implican que los tres tipos de signo van estrechamente vinculados entre sí, y también con los signos internos. El decrecimiento en la frecuencia de los $2 \mathrm{P}$ significa que se transforma paulatinamente la estructura del enunciado, pasando del largo período plurimembre a una oración más breve, en particular en $g$-i. Parece natural que la grafía deslinde por medio de espacios muy perceptibles (párrafos internos) los largos apartados de la parte A (véase 10r, 19v). Correlativamente, 
en la parte $\mathrm{B}$, mientras se va simplificando el enunciado, tiende a convertirse el párrafo en macroestructura textual básica: basta ya como frontera el núcleo [P B1 M] (65v-66r), que a veces se reduce incluso a [P M] (65v8, 65v30). Desde luego, se trata de una tendencia (en la expresión del gramático y en la representación escrita del impresor), y no escasean dentro del párrafo de la parte B, en ocasiones muy largo, los párrafos internos $(63 \mathrm{v}-64 \mathrm{r})$.

La variación de la tríade simbólica final/principio de enunciado resulta, por otra parte, de singular interés para la historia de la escritura y la historia del discurso escrito en España. El elemento menos imprescindible, el blanco, puede cancelarse en un contexto particularmente apretado (21v15 y 21v21, entre punto e $<\mathrm{J}\rangle$ - cada línea presenta dos abreviaturas-). Por el contrario, si se suprime el punto, es preciso restablecer el blanco para que la mayúscula cobre su significado de 'final de enunciado': «en nues /tra lengua La tercera regla» (17r22). Esta condición admite, sin embargo, una excepción; el final de línea actúa con frecuencia como puntuación implícita fuerte, reduciéndose la tríade al esquema $[/ \mathrm{M}]$ (sin punto ni blanco): «lodo/La.u.» (14r9). Si desaparece la mayúscula, la secuencia [P B $i]$ queda ambigua, ya que el punto puede tener en este caso otras dos funciones, puntuar un ejemplo (al igual que la coma moderna), o señalar una articulación interna de enunciado (como por lo común los $2 \mathrm{P}$ ). Su papel exacto sólo se deducirá del contexto. Cabe subrayar la situación particular de la $\langle\tau\rangle$, que no tiene mayúscula y, por tanto, se mantiene idéntica cuando funciona como separador de enunciados; es constante la duda, puesto que entre las 1202 ocurrencias de $y$ sólo se recogen $24<\mathrm{E}>$ y $62<\mathrm{J}>$, pero viene limitada por los empleos explícitos como articulación interna ([B $y \mathrm{~B}]$ y $[2 \mathrm{P}(\mathrm{B}) y])$.

Otro caso particular es el de los títulos. Suelen ir tratados como enunciados no frásticos en una secuencia de tres elementos, mención de capítulo, número y título, v. g. «Capitulo.ij. Del nombre.» (III, 29r23). En ocasiones, la mayúscula del título se convierte en minúscula: «Capitulo.x.delas coplas del castellano» (II, 27v29), resultando muy ambiguo el estatus discursivo del último segmento, ya que un número romano se escribe normalmente entre dos puntos sin que el segundo señale un final de enunciado. Puede interpretarse entonces mención de capítulo y título como una secuencia única en la que el título se subordinaría a la mención de capítulo, lo que efectivamente se verifica cuando se sustituye el número romano por su expresión léxica: «Capitulo primero delos acidentes dela silaba» (II, 17v26); pero incluso en este caso se observa una vacilación latente: «Capitulo sexto. Delos consonantes» (II, 22r33), «Capitulo quinto Delos / nombres verbales» (III, 33r33), predominando, sin embargo, el tratamiento del título como segmento autónomo, comience o no por un subordinante: «Libro tercero.que es dela etimologia» $(28 \mathrm{v} 32)$.

Estas observaciones resaltan la importancia contrastiva de la mayúsucla en la historia del enunciado, en relación con la puntuación y los espacios. Un 
empleo extremo del valor separativo de la mayúscula se nota en la cita interna de versos: «Como juan de mena. Ala biu/da Pen|[e]lópe.J al hijo de liriópe.» (19r22). Con ella, no sólo se respeta la identidad de cada verso, sino que se le otorga globalmente a la cita entera una situación específica en la sintaxis del enunciado. Bastará con añadir el aparte inicial y final para que la cita se convierta en una serie de párrafos externos pro forma, modelo que se aplicará también a las enumeraciones de ejemplos, comp.

Despide plazer.

J pone tristura. (rondel citado en 26r17)

$\mathrm{y}$

Agradecido el que agradece.

Mirado el que mira. (ejemplos de participios activos en 41v16).

Por supesto que el profundo cambio que al respecto se aprecia en la parte B no elimina completamente las antiguas costumbres. El libro IV sigue incorporando versos sin suspender el discurso, a veces sin mayúscula inicial: « $\tau$ juan / de mena dix̃o. do fue bautizado el fi de maria.por hi/jo de maria.» (50r20), pero en cuanto la cita comprende dos versos se hace fuera de texto, llevando cada verso una mayúscula inicial y un punto final $(50 \mathrm{r} 31)^{27}$.

Aunque resulta muy arduo discriminar en los diversos aportes lo que puede atribuirse al impresor y lo que se deberá al autor, de lo que no cabe duda es que, a pesar de su brevedad, el tratado va cobrando poco a poco un perfil didáctico cada vez más tangible, que queda manifiesto tanto en la evolución de la sintaxis como en la relativa normalización de la tipografía. A este respecto el testimonio documental de la $G C$, que hasta ahora tan poco se ha aprovechado, demuestra cuán inexacta parecerá a unos treinta años de distancia la apreciación de Colin Clair, gran conocedor sin embargo de la imprenta en Europa:

La posición apartada de España junto con el conservadurismo innato de los españoles [sic] imposibilitaba cualquier cambio rápido de moda. Los impresores permanecieron fieles a la tradición manuscrita cuando ya hacía tiempo que se había abandonado en otros lugares. (pág. 243) ${ }^{28}$

Si puede justificarse en relación con muchos textos, y entre ellos textos de ficción (Cárcel de amor, Sevilla, 1492, Pablo de Colonia, Juan Pegnitzer de

\footnotetext{
${ }^{27}$ Ambas características se desvanecen en una transcripción moderna como la de la Biblioteca Castro: «pudieras ver a Tereo, / a Idas, Arcas Anceo / colgar de agudas escarpias / y bañarse las tres Harpias / en la sangre de Phineo.» (Juan de Mena, Obra completa, ed. y pról. de Á. Gómez Moreno y T. Jiménez Calvente, Madrid, Turner, 1994, pág. 181).

${ }^{28}$ Colin Clair, Historia de la imprenta en España, ed. y pról. de J. Martín Abad, Madrid, Ollero \& Ramos, 1998, 678 págs. [ed. orig. A History of European Printing, 1976].
} 
Nuremberga, Magno Herbst von Fils, Tomás Glockner; Celestina, Burgos, 1499, Fadrique de Basilea — ique no son obra de impresores españoles! — ${ }^{29}$ ), la $G C$, precisamente, contrasta con ellos, constituyendo un capítulo de capital importancia en la historia de la escritura en España. Como síntesis (con lagunas) del pensamiento gramatical medieval y antiguo aplicado a una lengua romance, es y seguirá siendo un monumento de prosa didáctica. Como libro ofrece una amplio abanico de soluciones innovadoras frente a la tradición manuscrita que, por cierto, permanece preponderante, pero ya se va adaptando a nuevas necesidades (porque están cambiando los gustos del público lector y porque la imprenta en cuanto técnica orienta hacia otras modalidades de representación textual). En cierta medida, la $G C$ para Juan de Porras y su equipo fue algo así como la oportunidad de experimentar un conjunto de modelos gráficos, que después utilizarían en otros libros. No se ha agotado, ni mucho menos, el examen librario intrínseco; es preciso completarlo y, para interpretarlo correctamente desde una perspectiva multidisciplinar (historia de la imprenta, de la grafía, de la prosa, de los paradigmas culturales, de las técnicas didácticas), cotejar los resultados con los resultados recogidos sobre otros libros impresos dentro y fuera de España. Exigirá mucho trabajo, pero el interés actual por la historia de la escritura deja pensar que se llevarán a cabo las investigaciones necesarias para mejorar nuestros conocimientos en este ámbito de singular complejidad.

\section{BIBLIOGRAFÍA}

Alemán, Mateo, Ortografía castellana, J. Rojas Garcidueñas, ed., T. Navarro, est. prelim., México, El Colegio de México, 1950.

Calvo Fernández, Vicente, Grammatica Proverbiandi. Estudio de la Gramática Latina en la Baja Edad Media Española, Münster, Nodus Publikationen, 2000.

Casas Rigall, Juan, «Ad grammaticos pertinent. La teoría de los vicios, figuras y tropos en diez gramáticas hispanas del siglo XV», La corónica, 24/2, 1996, págs. 78-102.

Casas Rigall, Juan, «Vicios gramaticales y licencias oratorias: un capítulo deturpado de la Gramática de Nebrija», Neophilologus, 81, 1997, págs. 539-549.

Casas Rigall, Juan, «Retórica y diccionarios: vitia gramaticales, figuras y tropos en el Universal Vocabulario de Alonso Fernández de Palencia», La corónica, 34/2, 2006, págs. 203-226.

Clair, Colin, Historia de la imprenta en España, ed. y pról. de Julián Martín Abad, Madrid, Ollero \& Ramos, 1998.

${ }^{29}$ Vid. el comentario que de la lámina 31 de su manual (Fernando de Rojas, Tragicomedia de Calixto y Melibea, Sevilla, c.1518-1520, J. Cromberger) hace Riesco Terrero (1995, pág. 188): «El criterio aplicado a la hora de establecer la impaginación ha sido el mismo seguido en los manuscritos, esto es, aprovechar al máximo la superficie disponible, hasta el punto de que el texto no ofrece ninguna solución de continuidad, a pesar de que se trata de un diálogo entre varios personajes». 
Codoñer, Carmen, «Las Introductiones latinae de Nebrija: tradición e innovación», en V. García de la Concha, ed., Nebrija y la introducción del Renacimiento en España, Salamanca, Universidad de Salamanca, 1983, págs. 105-122.

Esparza Torres, Héctor, Las ideas lingüísticas de Antonio de Nebrija, Münster, Nodus Publikationen, 1995.

Gimeno Blay, Francisco M. y Trenchs Odena, José, «Libro y bibliotecas en la Corona de Aragón (siglo XVI)», en M. L. López-Vidriero y P. M. Cátedra, coords., El Libro antiguo español. Actas del Segundo Coloquio internacional (Sevilla, 1989), Salamanca, Universidad de Salamanca y Madrid, Biblioteca Nacional, Sociedad Española de Historia del Libro, 1992, págs. 207-239.

Infantes, Víctor, «1492: una cultura entre el libro y el lector», en P. Ruiz Pérez, ed., Gramática $y$ humanismo. Perspectivas del Renacimiento español, Madrid, Ediciones Libertarias y Ayuntamiento de Córdoba, 1993, págs. 57-85.

Martín Abad, Julián, Los primeros tiempos de la imprenta en España (c. 1471-1520), Madrid, Laberinto, 2003.

Martín Abad, Julián, Los Libros impresos antiguos, Valladolid, Universidad de Valladolid, Secretariado de Publicaciones e Intercambio Editorial, 2004.

Mena, Juan de, Obra completa, ed. y pról. de Á. Gómez Moreno y T. Jiménez Calvente, Madrid, Turner, 1994.

Nebrija, Antonio de, Gramática de la lengua castellana, A. Quilis, ed., Madrid, Editorial Centro de Estudios Ramón Areces, 1990.

Pellen, René, «Transcription des incunables, histoire de l'écriture et diachronie. Étude critique de l'édition du V Ventenaire de la Gramática castellana par Esparza et Sarmiento (1992)», Bulletin Hispanique, 108/1, 2006, págs. 67-222.

Pellen, René, «La referencia en la transcripción (informática) de los textos antiguos. Ejemplos nebrisenses», Revista de Filología Española, LXXXIX/2, 2009, págs. 349-360.

Pellen, René y Tollis, Francis, La «Gramática castellana» d'Antonio de Nebrija: grammaire d'une langue, langue d'une grammaire, Limoges, Lambert-Lucas, 2 vols., 2011.

Riesco Terrero, Ángel, Ruiz García, Elisa, Domínguez Aparicio, Jesús y Sánchez Prieto, Ana Belén, Aproximación a la cultura escrita, Madrid, Playor, 1995.

Rojas, Fernando de, Tragicomedia de Calixto y Melibea, Sevilla, J. Cromberger, c.1518-1520.

Fecha de recepción: 1 de septiembre de 2010

Fecha de aceptación: 4 de marzo de 2011 